\title{
Complications of Neck Dissection
}

\author{
Nader Saki and Soheila Nikakhlagh \\ Cancer Research Center of Ahvaz Jundishapur University of Medical Science,
}

Iran

\section{Introduction}

Head \& neck cancer is the major problem due to its associated morbidity and mortality. It is the sixth most common cancers and the eighth cause of cancer mortality in the world(1). The most important prognostic factor in the management of head and neck cancer is the presence of cervical lymph node metastasis. Neck dissection has been a well-established procedure for diagnosing (staging) and treating head and neck cancer for almost a century(2). This procedure is used to eradicate metastases to the regional lymph nodes of the neck. Since Crile introduced radical neck dissection at the beginning of the 20th century, a few changes have been proposed by Hays Martin in 1951 and Suárez which aimed for a more conservative approach to preserve vital anatomical structures in the neck without compromising the completeness of lymph node removal. The transition from radical to selective neck dissection has resulted in fewer complications and lower morbidity, at the same time preserving surgical efficacy and compliance with oncologic principles.(4)

Depending on the location and extent of the tumor, the type of neck dissection performed may be radical, modified, selective and extended and either unilateral or bilateral. Complications of neck dissection affect every surgeon regardless of experience and technical skill. In addition to the various medical complications that may occur after any surgical procedure in head \& neck region, a number of surgical complications may be related to the neck dissection. Complications of neck dissection are divided into three major categories: wound complications, Nerve complications, Vascular complications. Co-morbidities such as cardiac, respiratory and hepatic disease are common place in patients undergoing neck dissections in either an elective or therapeutic sense. Additional immunosuppression caused by conditions such as diabetes or relative malnutrition should be optimised since they predispose to complications including as wound infection. (5)

\section{Prevention of complications}

A careful history begins any thorough surgical evaluation. The surgeon should inquire about prior surgery and tumor therapy. Previous neck surgery may have an impact on incision design. Careful study of the lesion to be excised is of great importance. Its precise location, size, firmness, and mobility with respect to surrounding structures should be noted(6). Prior radiation therapy also slows healing, thus heightening the risk of postoperative complication. Patients should be encouraged to cease smoking as long before surgery as possible. Smoking exacerbates pulmonary dysfunction and may impair vascular perfusion, resulting in flap loss. The importance of communication between the anaesthetic 
and surgical teams cannot be over emphasised. There are theoretical advantages to using low-molecular weight as opposed to standard low dose heparin in the prophylaxis of deep vein thrombosis and pulmonary emboli since it lessens bleeding complications, has a prolonged duration of action and is less likely to induce thrombocytopaenia. $(2,7)$

Intraoperative events, such as hemorrhage, loss of a venous suture resulting in gas embolism, chylous leakage due to thoracic duct injury, and arrhythmia because of carotid bulb manipulation, are habitually promptly managed; these events may, however, be disastrous for the patient. Careful dissection and ligature of vessels are extremely important to avoid intra-and postoperative hemorrhage. (8)

\section{Wound complications}

Although preparation of a surgical site prevents wound contamination by removing transient pathological bacteria and decreasing resident flora counts, good surgical technique with minimal tissue damage still has a role to play. Removal of large amounts of beard hair may increase the rate of infection unless carried out immediately prior to surgery. A variety of approaches exist for the approach to neck dissections that usually simply rely on surgeon preference, e.g. martin double-Y incision, apron access $(7,9)$.

The incidence of wound infection after surgery of the neck without entry into the aerodigestive tract should be very low. Prophylactic antibiotics may be continued during the first 24 to 72 postoperative hours. Wound infection is a contributing factor to dehiscence and flap skin loss. Others include poor nutrition, prior radiation therapy, poor incision and flap design, and continued smoking during the perioperative period. Skin Flaps should be elevated in the sub-platysmal plane in order to maximise their blood supply unless local disease dictates otherwise. Flap elevation superficial to the platysma adds to the prolems of skin loss(3,8).(fig1)

Wound infection may manifest as a cellulitis with erythema, warmth, or induration of the cervical skin flaps, abscess formation from an infected seroma or hematoma, or fistula (12). Once a wound infection is detected, action must be taken to minimize sequelae.Wound Complications after neck dissection are associated with increased patient morbidity and hospitalization. Other complications are also possible such as: Undesired Scarring, Flattened Appearance and Pain.

\section{Nerve complications}

\subsection{Sensory branches of the cervical roots}

Sensory branches of the cervical roots provide sensation to skin of the neck and shoulder. As the skin flaps are elevated in subplatysmal plane, several branches of the cervical plexus are immediately encountered overlying the SCM. Sacrifice of these branches will results in a sensory deficit that extends from pinna to the chest wall below the clavicle. Most of this sensory deficit will spontaneously resolve postoperatively over a period of months. Branches of the cervical plexus can also form neuromas, which present as firm, painful masses in the lateral neck that are exquisitely tender to palpation(9).

\subsection{Greater auricular nerve}

The greater auricular nerve serves as an excellent landmark for the proper plane for elevation of the skin flap, because it lies lateral to the SCM. The nerve should be kept down 


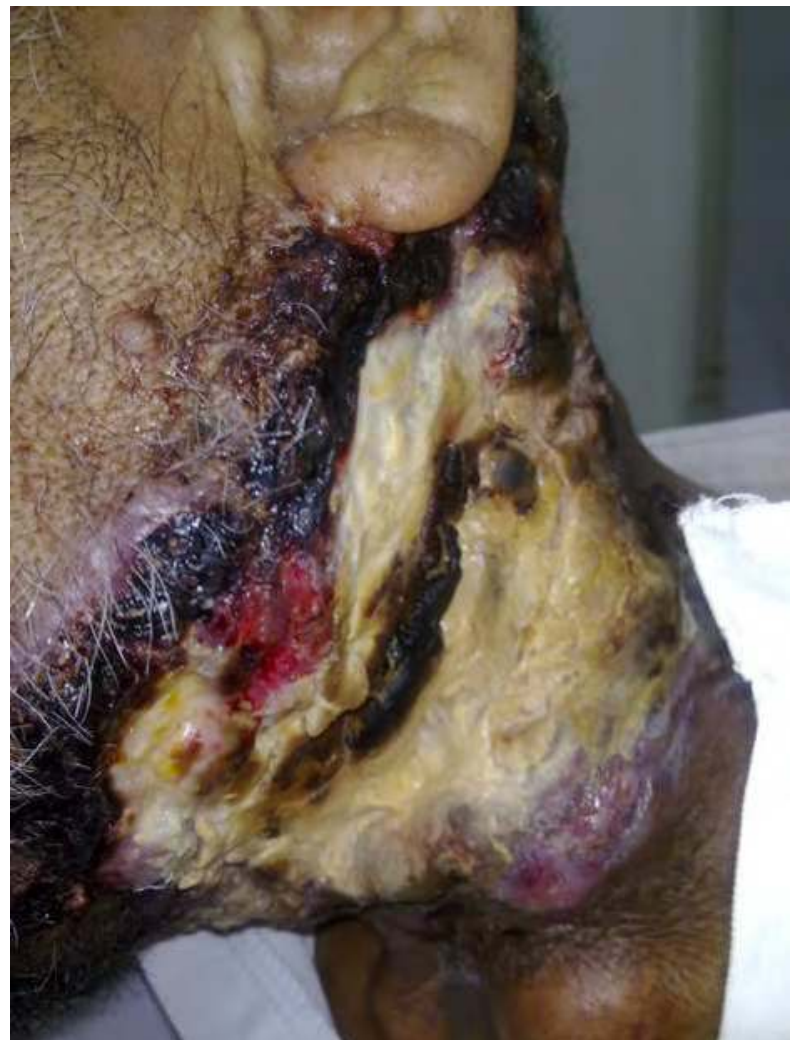

Fig. 1. Wound infection and necrosis

on the SCM during flap elevation, and the decision of whether to preserve it can be made later. Sacrifice of this nerve during neck dissection leads to a sensory deficit of the auricle that usually diminishes with time. Neuroma of divided greater auricular nerve can occur(10).

\subsection{Lingual nerve}

The lingual nerve is primarily a branch of the mandibular division of the trigeminal nerve( cranial nerve $\mathrm{V}$ ) that carries general sensation from the anterior two thirds of the tongue. It also receives the chorda tympani nerve from the facial nerve, which carries taste from the same region of the tongue. Level I neck dissection incorporating submandibular gland excision puts this nerve at risk for injury. Clinically, injury results in loss of taste from ipsilateral anterior two third of the tongue and hypoesthesia or paresthesia of the hemitongue with resultant difficulty with speech and deglutition(4).

\subsection{Facial nerve}

During standard neck dissection usually the cervical and marginal mandibular branches of the facial nerve are encountered. The Cervical branch of facial nerve innervates the platysma muscle. Sacrifice of the cervical branch does not uaually produce clinically significant deficits. 
The marginal mandibular branch of the facial nerve is typically single branch and its position with respect to the body of the mandible is highly variable. Injury to this nerve causes an obvious cosmetic deformity with asymmetry of the motion of the corner of the mouth. The marginal mandibular branch can be preserved by ligation and superior retraction of the facial vein. The branch is thus rolled up with the skin flap and kept away from further surgical dissection(3).

\subsection{Spinal accessory nerve}

The Spinal accessory nerve consists entirely of motor fibers to the SCM and Trapezius muscle. Prevention of injury of the nerve is achieved by proper identification of the Spinal accessory nerve using standard landmark and meticulous handling of the nerve once identified. Sacrifice of or damage to the Spinal accessory nerve (cranial nerve XI) is a major contributing factor to complaints related to the shoulder. Pain and weakness of the shoulder are among the most common postoperative complications of neck dissection(11).

\subsection{Vagus nerve}

Whether the surgeon plans to sacrifice or preserve the internal jugular vein, it is necessary to first identify all of the structures in the carotid sheath. Inadvertent injury to the vagus nerve may occur during the process of ligation the internal jugular vein in the inferior neck or at the skull base. High vagus nerve injuries result in significant dysphonia from ipsilateral vocal cord paralysis and dysphagia with pooling of secretions from pharyngeal paralysis and loss of sensation in the larynx. A breathy voice, an inefficient cough, and a subjective sense of dyspnea result. The loss of more distal vagal innervations has little clinical effect(4).

\subsection{Hypoglossal nerve}

Hypoglossal nerve injury is a rare complication of neck dissection. The nerve is susceptible to injury during dissection of level I,II, near the greater cornu of hyoid bone and adjacent to the carotid artery. Hypoglossal nerve injury result in ipsilateral tongue weakness, deviation of the tongue to the affected side and difficulty with speech and swallowing(5).

\subsection{Phrenic nerve}

The phrenic nerve arises from $\mathrm{C} 3, \mathrm{C} 4$ and $\mathrm{C} 5$ and it courses between the anterior scalene muscle and its overlying fascia. As elevation of the contents of the posterior triangle proceeds from the trapezius toward the carotid sheath, the cervical plexus contributions to the phrenic nerve or to a loop of the phrenic nerve itself may be injured. phrenic nerve paralysis is considered a rare complication of neck dissection and leads to ipsilateral hemidiaphragm elevation with or without mediastinal shift on chest radiograph, and it may contribute to postoperative pulmonary complications. Preservation of the fascial layer over the nerve and anterior scalene muscle is the primary method for prevention of injury. Fluoroscopic examination postoperatively confirms the diagnosis of phrenic nerve injury(6).

\subsection{Sympathetic nerve}

The fusiform cervical sympathetic gangion consists of two to four ganglia running parallel and deep to the carotid sheath. There is rarely any reason to enter this area during tumor 
removal in neck dissection, but, injury can occur during retraction of the carotid sheath to clear tumor or adjacent lymph nodes and may be temporary, related to traction or permanent due to transaction. The neurologic deficit caused by injured to the cervical sympathetic nerves depends on the site of injured. A classic Horner syndrome consists of the following ipsilateral conditions: Miosis, Ptosis, Anhydrosis, Transient blush and nasal congestion. No Horner syndrome will results from an injured below the stellate gangion located behind the vertebral artery in the root of the neck $(8,11)$.

\subsection{Brachial plexus}

Lateral to the phrenic nerve beneath the fascial floor of the posterior triangle is the brachial plexus, which is wedged between the sclanenus muscles. This structure, like the phrenic nerve, is deep to the deep cervical fascia, and it should be easily preserved when gentle blunt dissection of the fat overlying the fascia is performed. Any fat that does not come away from the floor of the posterior triangle with gentle blunt dissection must be cautiously examined to be certain that there is no nerve running within. If a nerve is present, the surgeon must decide whether to dissect it free of the surrounding fat or to leave the fat at the floor of the dissection(8).

\section{Vascular complicatioms}

\subsection{Hematoma}

Hematoma occurs in approximately $1 \%$ of the neck dissections. Failure to recognize and properly treat a hematoma results in increased wound complications. Prevention consists of preoperative avoidance of anticoagulants and antiplatelet agents and meticulous intraoperative hemostasis. Careful dissection and meticulous hemostasis during surgery are extremely important to avoid intra-and postoperative hemorrhage. Hematomas are avoided by careful hemostasis, application of pressure dressing and continuous suction drainage. Most introperative complications may be prevented by means of careful surgical technique, coupled with a thorough understanding anatomy of head \& neck(8).

\subsection{Internal jugular vein complications}

It is important to clear the upper jugular nodes thoroughly, because they are common sites for tumor recurrence. The internal jugular (IJ) has several large tributaries that enter it anterosuperiorly. If it is to be spared, care must be taken to ligate these branches well away from the wall off the preserved vein. Narrowing of the vein probably contributes to the postoperative thrombosis and occlusion that are reported to occur in $15 \%$ of preserved jugular vein. Thrombosis of the internal jugular (IJ) vein is an underdiagnosed condition that may occur as a complication of head and neck infections, surgery, central venous access, local malignancy, polycythemia, hyperhomocysteinemia, neck massage, and intravenous drug abuse. It is also reported to occur spontaneously. IJ thrombosis itself can have serious potentially life-threatening complications that include systemic sepsis, chylothorax, papilledema, airway edema, and pulmonary embolism. The diagnosis often is very challenging and requires, first and foremost, a high degree of clinical suspicion. If the Internal jugular vein is to be ligated during neck dissection, it should first be thoroughly exposed, with the position of the vagus and hypoglossal nerves being noted(7). 


\subsection{Carotid artery complications}

Complications involving the common carotid artery are the most feared sequelae of neck surgery. Acute postoperative carotid artery rupture, or "blow out" occurs in $3 \%$ to $4 \%$ of radical neck dissection and associated with a mortality rate of $50 \%$. Factors associated with carotid artery hemorrhage include wound breakdown, necrosis, and infection, pharyngocutaneous fistula, prior radiation therapy, tumor involvement of the arterial wall. Tumor invasion of the carotid artery is a relatively uncommon event of advanced aggressive disease or revision surgery for a recurrent neck mass(4).when wound dehiscence results in the exposure of the carotid artery,it is more ominous, and its management more critical.(fig2)

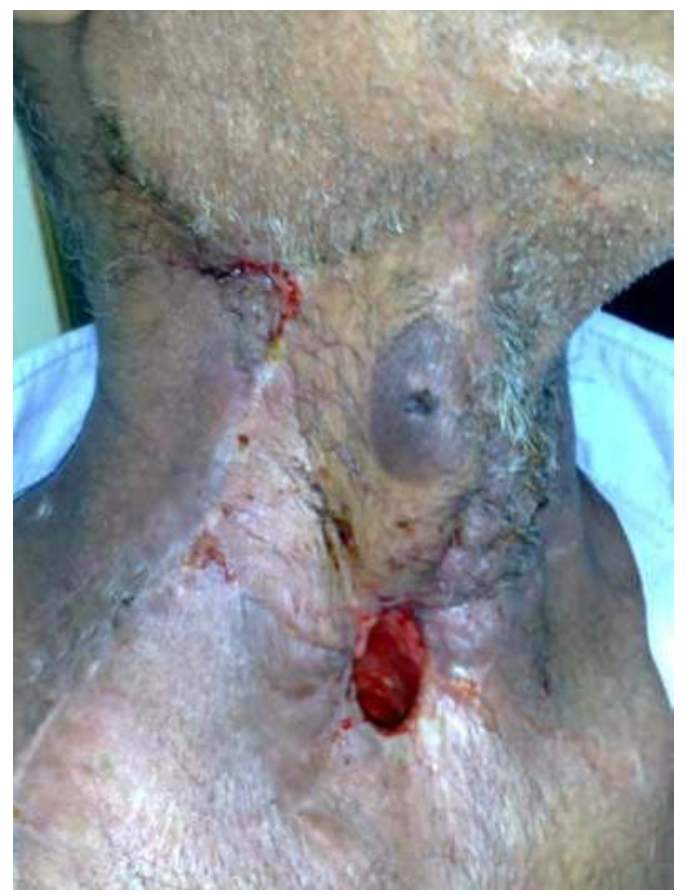

Fig. 2. Pectoralis major flap for coverage of exposed carotid artery

\subsection{Chyle fistula}

The thoracic duct arises from the cisternal chyli at the level of the second lumbar vertebra and rises into the neck between the aorta and the azygos vein. In the thorax it crosses to the left and after passing behind the aortic arch and left subclavian artery it lies on the anterior scalene muscles and phrenic nerve. The duct terminates most commonly in the left IJV although less commonly it may enter the left subclavian, left external jugular, left brachiocepalic (innominate) vein or right IJV. Up to $50 \%$ of patients exhibit more than one termination of the duct. The right lymphatic duct drain terminates at the junction of the right subclavian vein and IJV. The key to treatment of a chyle fistula is prevention which demands knowledge of the relevant anatomy. Whereas intra-operative identification can be 
aided by placing the patient in the Trendelenburg position or adopting a forced Valsalva manoeuvre, post-operative leaks are usually identified when feeding is commenced. Multiple approaches to the treatment of an established leak have emerged including nutritional, surgical and pharmalogical therapy. Although there are strong feelings amongst clinicians about the use of bowel rest, parental nutrition or low fat enteral formulae for the treatment of established chyle leaks, definitive evidence supporting one therapy over another does not exist (4).

\section{Conclusion}

Surgery of the neck requires a high level of expertise and familiarity with the complex anatomy of the region. Complications in neck surgery may occur despite the best efforts to prevent them. Proper preoperative planning, early recognition of perioperative complications, and prompt, effective management can minimize the impact of complications that may occur.

\section{References}

[1] Kazi, RA. "The Life and Times of George Washington Crile: An Outstanding Surgeon." The Internet Journal of Otorhinolarygology. 2003. Vol 2, No 2.

[2] Shaha, A. 2007. "Editorial: Complications of Neck Dissection for Thyroid Cancer." Annals of Surgical Oncology. Accessed: August 19, 2010. Available at: http://www.ncbi.nlm.nih.gov/pmc/articles/PMC2244697/.

[3] Ferlito, A et al. Neck Dissection: past, present and future? J. Laryngol Otol. 2005 (1) 1-6.

[4] Smoke A, Delegge MH: Chyle leaks: consensus on management? Nutr Clin Pract 2008, 23(5):529-32. PubMed Abstract | Publisher Full Text

[5] Walker FD, Cooke LD: Antimicrobial prophylaxis in otorhinolaryngology/head and neck surgery. Clin Otolaryngol 2007, 32(3):204-7. PubMed Abstract | Publisher Full Text

[6] Lauchlan DT, McCaul JA, McCarron T: Neck dissection and the clinical appearance of post-operative shoulder disability: the post-operative role of physiotherapy. Eur J Cancer Care (Engl) 2008, 17(6):542-8. PubMed Abstract | Publisher Full Text

[7] Prim MP, De Diego JI, Verdaguer JM, Sastre N, Rabanl I:Neurologic complications following neck dissection .Eur Arch Otorhinolaryngol 2006, 263(5):473-6. PubMed Abstract | Publisher Full Text

[8] Tatla T, Kanagalingam J, Majithia A, Clarke PM: Upper neck spinal accessory nerve identification during neck dissection. J Laryngol Otol 2005, 119(11):906-8. PubMed Abstract | Publisher Full Text

[9] Weiss KL, Wax MK, Haydon RC 3rd, Kaufman HH, Hurst MK: Intracranial pressure changes during bilateral radical neck dissections. Head Neck 1993, 15(6):546-52. PubMed Abstract | Publisher Full Text

[10] Brown DH, Mulholland S, Yoo JH, Gullane PJ, Irish JC, Neligan P, Keller A: Internal jugular vein thrombosis following modified neck dissection: implications for head and neck flap reconstruction. Head Neck 1998, 20(2):169-74. PubMed Abstract | Publisher Full Text 
[11] Prim MP,De Diego JI,Verdaguer JM. Neurological complications following functional neck dissection. Eur Arch Otorhinolaryngol.2006;263(5):473-476.

[12] Nader Saki, Soheila Nikakhlagh , Maryam Kazemi. Pharyngocutaneous Fistula after Laryngectomy: Incidence, Predisposing Factors, and Outcome. Arch Iranian Med 2008; 11 (3): $314-317$ 


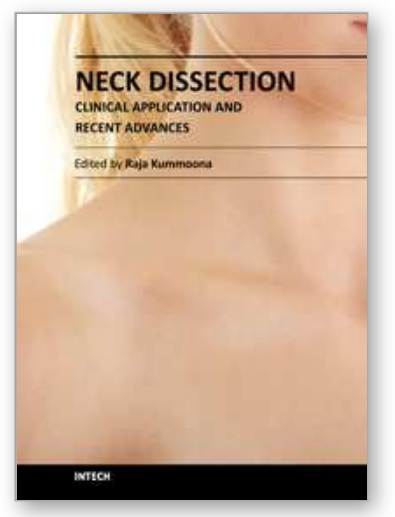

\author{
Neck Dissection - Clinical Application and Recent Advances \\ Edited by Prof. Raja Kummoona
}

ISBN 978-953-51-0104-8

Hard cover, 164 pages

Publisher InTech

Published online 22, February, 2012

Published in print edition February, 2012

Neck Dissection - Clinical Application and Recent Advances is a leading book in neck surgery and represents the recent work and experiences of a number of top international scientists. The book covers all techniques of neck dissection and the most recent advances in neck dissection by advocating better access to all techniques of neck dissection; e.g. Robotic surgery (de Venice) system, a technique for detection of lymph node metastasis by ultra sonography and CT scan, and a technique of therapeutic selective neck dissection in multidisciplinary treatment. This book is essential to any surgeon specializing or practicing neck surgery, including Head Neck Surgeons, Maxillofacial Surgeons, ENT Surgeons, Plastic and Reconstructive Surgeons, Craniofacial Surgeons and also to all postgraduate Medical \& Dental candidates in the field.

\title{
How to reference
}

In order to correctly reference this scholarly work, feel free to copy and paste the following:

Nader Saki and Soheila Nikakhlagh (2012). Complications of Neck Dissection, Neck Dissection - Clinical Application and Recent Advances, Prof. Raja Kummoona (Ed.), ISBN: 978-953-51-0104-8, InTech, Available from: http://www.intechopen.com/books/neck-dissection-clinical-application-and-recent-advances/complicationof-neck-dissection

\section{INTECH}

open science | open minds

\section{InTech Europe}

University Campus STeP Ri

Slavka Krautzeka 83/A

51000 Rijeka, Croatia

Phone: +385 (51) 770447

Fax: +385 (51) 686166

www.intechopen.com

\section{InTech China}

Unit 405, Office Block, Hotel Equatorial Shanghai

No.65, Yan An Road (West), Shanghai, 200040, China 中国上海市延安西路65号上海国际贵都大饭店办公楼 405 单元

Phone: +86-21-62489820

Fax: +86-21-62489821 
(C) 2012 The Author(s). Licensee IntechOpen. This is an open access article distributed under the terms of the Creative Commons Attribution 3.0 License, which permits unrestricted use, distribution, and reproduction in any medium, provided the original work is properly cited. 